\title{
Structural Identification of Masonry Residential Buildings Considering Wall Openings
}

\author{
Burak Toydemir $^{1 *}$, Ali Koçak² \\ ${ }^{1}$ Construction Department, İstanbul Gelişim Vocational School, İstanbul Gelişim University, Cihangir Mahallesi, Petrol Ofisi Caddesi \\ No. 7, 34310, Avcılar, İstanbul, Turkey \\ 2 Department of Civil Engineering, Faculty of Civil Engineering, Yıldız Technical University, Davutpaşa Campus, 34220, Esenler, İstanbul, \\ Turkey \\ * Corresponding author, e-mail: btoydemir@gelisim.edu.tr
}

Received: 11 May 2020, Accepted: 20 July 2020, Published online: 16 September 2020

\begin{abstract}
Although one-story residential masonry structures are thought not to be vulnerable to seismic actions, many heavily damaged and/ or collapsed instances of these types of structures have been observed in the past strong earthquake events. Hence, the evaluation of their safety requires much attention in terms of more precise numerical models. In-situ vibration tests together with laboratory tests on masonry specimens provide valuable information for structural parameter identification that can be used to develop accurate numerical models. These numerical models then can be used for evaluation of the response and seismic safety. While many specific methods and parameters can be adopted in numerical modeling, linear material properties of a structure are expedient in response analysis. Hence, an equation to be used to determine the homogenized linear model parameters for masonry walls with openings is proposed in this study. The equation has been developed based on the percentage of the openings on the wall. The effect of wall openings on the stiffness and the total strength of one-story masonry structures have been evaluated by using the experimental data and the calibrated finite element models. In-situ ambient vibration and material tests have been conducted on three masonry buildings with identical materials and the results from these experiments were used to verify the accuracy of the formulation.
\end{abstract}

Keywords

masonry, wall openings, Operational Modal Analysis, structural identification, time history analysis

\section{Introduction}

Masonry is known as one of the oldest engineering structures in the world. Determining the mechanical properties of masonry units is challenging, yet, vital to understand the behavior of masonry structures. The complex structural details of masonry structures make it difficult to determine these mechanical properties accurately. While mechanical values of mortar and masonry units contribute to the behavior of the masonry wall, interaction between mortar and masonry unit also affects the structural response. There are different researches related to investigating the behavior of the masonry structures.

While there are multiple approaches to determine the behavior of the masonry buildings, there are on-site measurements to define the mechanical and dynamic properties of the masonry structures. As the safety of a structure is essential in the engineering perspective, determining the dynamic characteristics have an important role. As in various seismic codes, there are several dynamic analysis methods described in the Turkish Seismic Code (TSC) in detail, to evaluate and ensure the safety of masonry structures as well. All of these analysis methods are based on using dynamic characteristics of the structures. Thus, accurate determination of the dynamic characteristics of a structure is of great importance. Although the dynamic characteristics of a structure can be determined by using analytical methods, in some cases, it might not be possible to get accurate or sufficient results. In these cases, there are some experimental analysis methods to extract the dynamic characteristics of a structure. One of those methods to determine the dynamic characteristics of the structures is Modal Analysis. In cases such as the structures that have been damaged from earthquakes or any other loads, analytical analysis results might not give accurate results for dynamic characteristics of structures as well. 
Modal analysis constitutes an important place in dynamic analysis of the damaged structures. There are researches on damaged structures for modal identification of dynamic parameters [1-6].

Dynamic characteristics determined by modal analysis can be used to

- Control the differences of dynamic characteristics on damaged buildings by pre and post modal analysis.

- Control the convergence of dynamic characteristics between the model and the actual structure

- Adjustment of the model based on the modal analysis results.

There are two types of modal analysis measurements, which are Operational Modal Analysis, and Experimental Modal Analysis. Conventionally, the Experimental Modal Analysis (EMA) is measuring the vibration response of the structure from the pre-determined loads to determine the dynamic characteristics. The main advantage of EMA is the data are collected by applying a pre-determined and controlled load. On the other hand, Operational Modal Analysis (OMA) has succeeded in attracting a lot of attention since the 1990s. OMA is a form of analysis that determines the dynamic characteristics of the structure during the operational stage. In Operational Modal Analysis, the loads, which cause the dynamic responses, are created by pedestrian movements, vehicle loads, wind loads, and micro-tremors. The main difference in OMA is the size and the forces that cause the vibrations to be unknown. Thus, it is called Output Only Modal Analysis as well. Operational Modal Analysis has multiple approaches to determine the modal parameters of a structure. Frequency Domain Decomposition (FDD), Enhanced Frequency Domain Decomposition (EFDD), and Stochastic Subspace Identification (SSI) [7-10].

While experimental analysis techniques give accurate results for the structures, the numerical analysis is also a valuable method for determining the dynamic characteristics of masonry structures. Two different modeling approaches are defined by Lourenço et al. [11] called Micro Modelling and Macro modeling. The research also shows that the masonry structure can show significant inelastic behavior due to the interaction between masonry and mortar. AlGohi et al. [12] studied the effect of axial force on lateral behavior of masonry walls and stated that linear response has limited capability to define the behavior of masonry walls under vertical loads. Micro modeling is accomplished by modeling mortar and masonry units separately and creating a contact interface between these basic elements. Variable modeling methods have been used to define the contact interfaces. Traction-Separation Law is one of the accurate modeling methods for contact interfaces for the masonry structures. Many pieces of research have been completed to define and investigate the behavior of masonry contacts by traction separation laws [13-19]. Besides, different contact interaction properties have been defined as well for masonry structures [20-24]. On the other hand, macro modeling accomplished by creating the 3D or 2D model as a single composite solid and assigning single material properties to represent the mechanical behavior of the masonry wall [25]. Variable modeling methods and material parameters have been investigated to determine the behavior of masonry structures and comparisons have been made with experimental analysis [26-30]. Plevris and Asteris [31] investigates the failure surface of the masonry structure with the help of neural networks.

In addition, the orthotropic damage model has been investigated for the masonry structures and accurate results have been conducted [32-34]. Macro mechanical models and extended finite element methods have also been used to analyze the behavior of the masonry walls. $[35,36]$

As investigated on the previous researches, accurate material definitions on a masonry structure have an important role in determining dynamic parameters. Linear stiffness is one of the most important parameters on a masonry structure for determining the dynamic parameters. In addition, the openings also have an important role on behavior of a masonry building. Due to the effect of stiffness loss on dynamic parameters, the stiffness loss caused by the openings on a masonry wall should be considered during the determination of the dynamic parameters.

In this study, the seismic response of three different masonry buildings have been investigated based on the evaluation of linear and non-linear behavior of masonry walls under lateral loading while considering openings on the walls.

First, operational modal analyses have been conducted on the investigated buildings and dynamic properties of the buildings have been extracted. In addition, lateral loading experiments have been conducted on the masonry walls with the identical mortar and masonry units as in the investigated buildings. In guidance of the linear and non-linear properties determined from the in-plane lateral loading experiment, 3D FE model have been constructed and calibrated based on the experimental results. In addition to the micro modeling of the walls, macro-modeling technique has been used to determine the initial stiffness of the walls as a composite material. 
Second, using the linear and non-linear material properties that have been determined by calibrated FE model, various masonry walls with openings has been created using micro modeling approach to realize the lateral response of the walls with the openings. In order to calculate the stiffness of the walls with openings, FE models have been analyzed and an equation related to the stiffness loss caused by the openings has been proposed. The accuracy of the proposed equation has been verified by comparing the results from FE model and the operational modal analysis conducted on three masonry structures built with the same materials.

Finally, linear time history analyses of the buildings have been conducted on the investigated buildings by using the linear and non-linear material properties calculated by proposed equation and macro models calibrated by experimental analysis.

\section{Experimental analysis}

Three different masonry buildings have been considered throughout this study. These masonry buildings are located in an active seismic region in Turkey.

All Buildings are single-story masonry structures. The areas of the buildings are $116 \mathrm{~m}^{2}, 104 \mathrm{~m}^{2}$, and $122 \mathrm{~m}^{2}$ for Building A, Building B, and Building $\mathrm{C}$, respectively. The buildings and structural layouts can be seen in Fig. 1.

\subsection{Ambient vibration tests on masonry structures}

Operational modal analysis (OMA) has been used to determine the accuracy of the model. As mentioned, there are multiple methods on OMA to extract the modal characteristics.
Enhanced Frequency Domain Decomposition is one of those methods to determine the modal characteristics of the structure. In a linear system, the function between the equation between the input and output can be seen as [37].

$\left[G_{y y}(\omega)\right]=[H(\omega)] \cdot\left[G_{x x}(\omega)\right] \cdot[H(\omega)]^{T}$

where $\left[G_{x x}(j \omega)\right]$ is Power Spectral Density matrix, $\left[G_{y y}(j \omega)\right]$ is the Power Spectral Density matrix of the responses and $[H(j \omega)]$ is the Frequency response Function Matrix. The Frequency response function can be written as: Herlufsen et al. [38].

$$
G_{y y}(j \omega)=\sum_{k=1}^{n} \frac{A_{k}}{j \omega-\lambda_{k}}+\frac{A_{k}^{*}}{j \omega-\lambda_{k}^{*}}+\frac{B_{k}}{-j \omega-\lambda_{k}}+\frac{B_{k}^{*}}{-j \omega-\lambda_{k}^{*}}
$$

and output Power Spectral Density can be written as

$$
G_{y y}(j \omega)=U_{i} S_{i} U_{i}^{h} \text {. }
$$

In this equation, $S$ is the singular value diagonal matrix and $U$ is the orthogonal matrix of singular vectors. The singular vectors are used to determine the mode shapes of the system and corresponding singular values are used to determine the response for each mode of the Single Degree Freedom Systems. OMA is conducted on the investigated buildings to determine actual modal frequencies. During OMA, the selected equipment, sampling rate of the data, measurement time, and measurement setup play an important role. The ambient vibration tests have been conducted with TEXTBOX 2010, which has 24 Bit ADC resolution and the dynamic range is $138 \mathrm{~dB}$. Sensebox $702 \mathrm{X}$ series

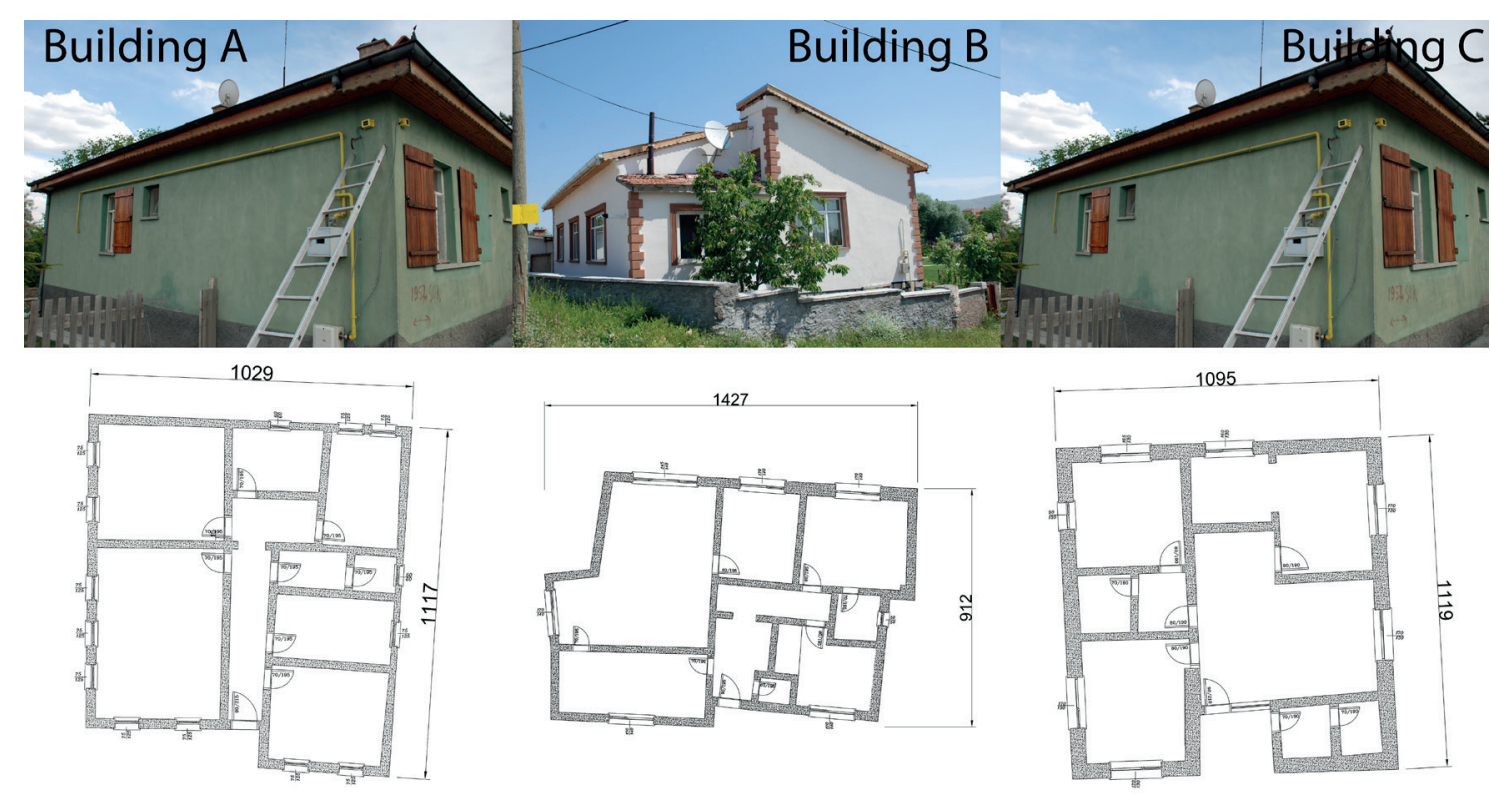

Fig. 1 Masonry buildings and structural layouts 


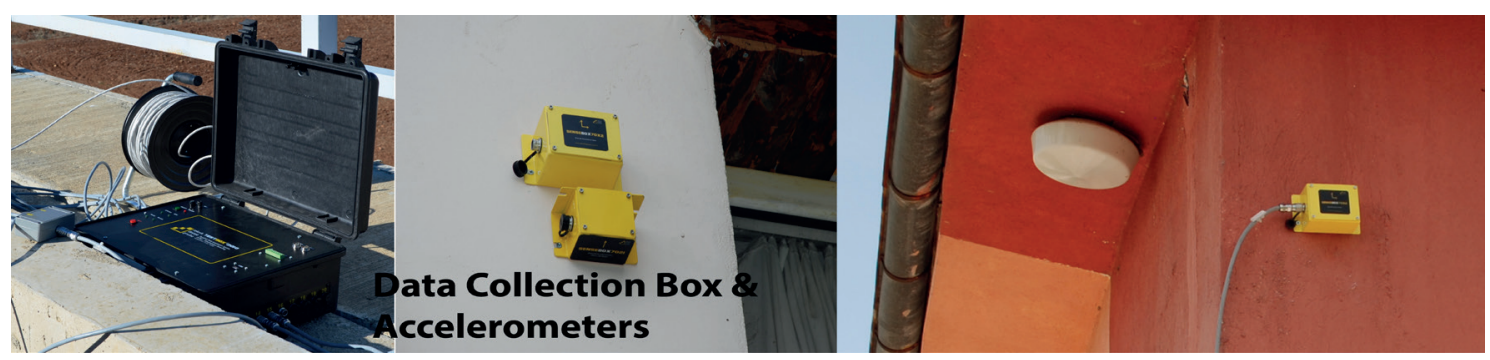

Fig. 2 Data collection box and accelerometers

accelerometers were connected to the TESTBOX 2010. The sensitivity of the accelerometers is between 2400 and $6000 \mathrm{mV} / \mathrm{g}$. The data was collected by uniaxial and bi-axial accelerometers. (Fig. 2)

The expected frequency span for the investigated buildings is between $10 \mathrm{~Hz}-40 \mathrm{~Hz}$ and based on the selection of frequency span of the buildings, 15 minutes of data with the sampling rate of $200 \mathrm{~Hz}$ would be adequate for OMA of the investigated structure.

The placements of the accelerometers are critical to estimate the modal frequencies. Based on the layout of the structure and modal analysis of the 3D Models, the accelerometers have been placed to the four corners of the building for $\mathrm{X}, \mathrm{Y}$ and $\mathrm{Z}$ directions.

The collected data from the accelerometers were being processed by Artemis, which is a software for signal processing and operational modal analysis. Detrending of the collected data and Butterworth functions have been used during the process of signals. While converting the signal from the time domain to the frequency domain, Fourier transformation was used by dividing the data into finite lengths. During the data collection, different linear trends can cause deflection in the results. Detrending is a necessary process for removing linear trends on the signal while converting signals from time domain to frequency domain to prevent inadequate results. Also, Butterworth bandpass filters have been used to filter frequencies between $5 \mathrm{~Hz}$ and $50 \mathrm{~Hz}$. The estimated modal frequencies are $10-40 \mathrm{~Hz}$ and filtering the signal makes it effective to evaluate the results. Filtered signals have been analyzed by Artemis Modal Analysis Software. Enhanced Frequency Domain Decomposition (EFFD) technique has been used to analyze the filtered data and extract the modal frequencies. The Singular Value Decomposition graphs have been determined and peaks on the singular value decomposition graph show the modal frequencies under ambient forces.

The singular value decomposition (SVD) graphs for buildings and the extracted modal frequencies have been shown in Fig. 3 for Building A, B and C, respectively.
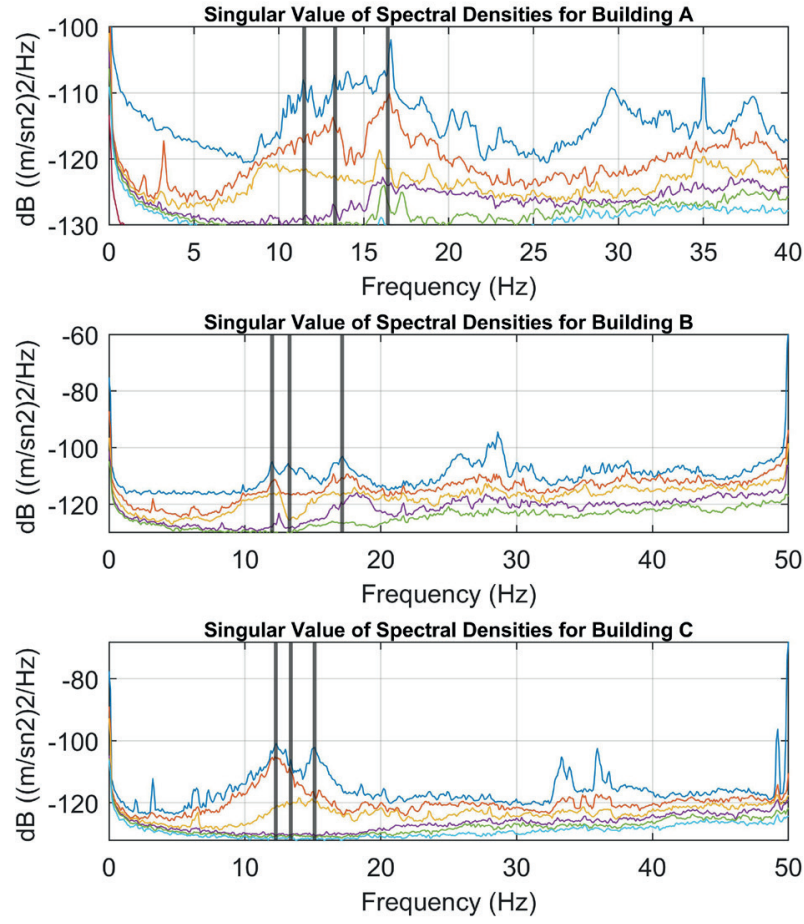

Fig. 3 EFFD analysis and SVD plots for the buildings

In addition to the fundamental modal frequencies for the investigated buildings. The mode shapes have been extracted by using the ambient vibration data. The mode shapes and the modal frequencies of Building A, Building B, and Building $\mathrm{C}$ have been given in Figs. 4, 5 and 6.

\subsection{Laboratory experiments on masonry wall}

The masonry walls used in these buildings consist of two materials: brick and mortar. $290 \mathrm{~mm} \times 190 \mathrm{~mm} \times 135 \mathrm{~mm}$ clay bricks, which is a common material for masonry structures in the region, have been used as a masonry unit. The lateral loading tests have been conducted on the walls with identical mortar and masonry units. Cement-based mortar has been used as a bonding agent in the masonry wall. During the production of the wall, 9 samples have been taken and mechanical tests have been conducted on the samples to determine the mechanical properties of the mortar (Fig. 7). 


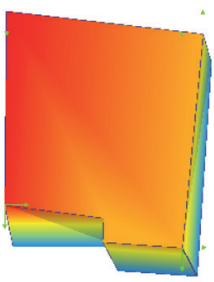

$f_{1}=11.50 \mathrm{~Hz}$

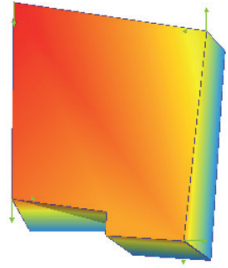

$f_{2}=13.31 \mathrm{~Hz}$

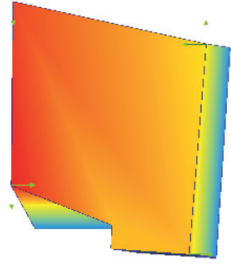

$f_{3}=16.42 \mathrm{~Hz}$
Fig. 4 OMA result for Building A

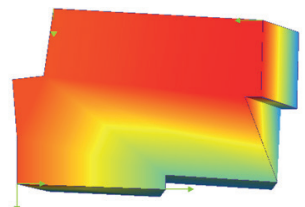

$f_{1}=12.00 \mathrm{~Hz}$

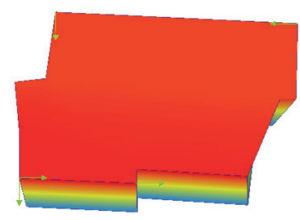

$f_{2}=17.16 \mathrm{~Hz}$
Fig. 5 OMA result for Building B

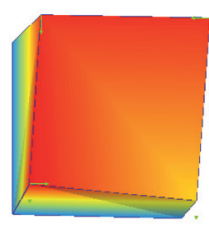

$f_{1}=12.25 \mathrm{~Hz}$

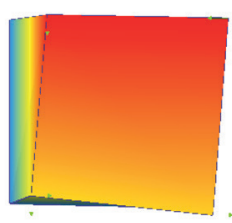

$f_{2}=13.38 \mathrm{~Hz}$

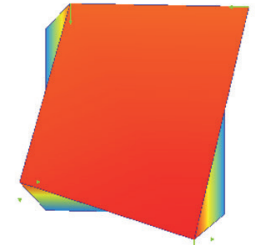

$f_{3}=15.12 \mathrm{~Hz}$
Fig. 6 OMA result for Building $\mathrm{C}$

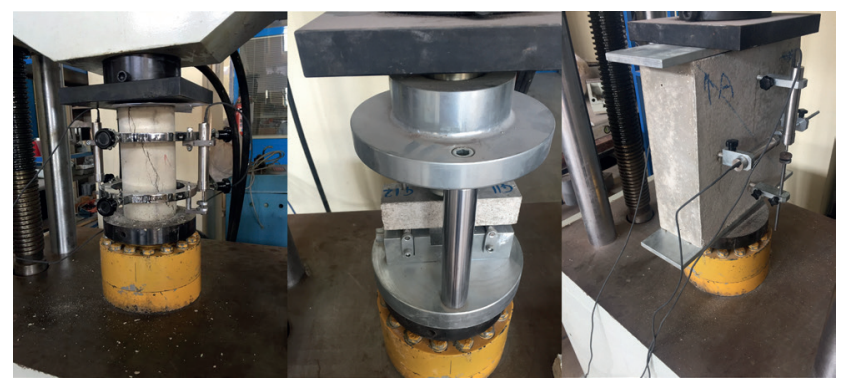

Fig. 7 Material tests

The compression and bending tests have been carried out to determine the compressive and the tensile strength of the brick, respectively. Young's modulus and Poisson ratio have been calculated as well. The results of the mechanical tests include modulus of elasticity, tensile strength, and compression strengths are shown in Table 1.
Table 1 Material properties

\begin{tabular}{lccccc}
\hline Material & $\begin{array}{c}\text { Density } \\
\left(\mathrm{N} / \mathrm{mm}^{3}\right)\end{array}$ & $\begin{array}{c}\text { Young's } \\
\text { Modulus } \\
(\mathrm{MPA})\end{array}$ & $\begin{array}{c}\text { Poisson's } \\
\text { Ratio }\end{array}$ & $\begin{array}{c}\text { Compressive } \\
\text { Strength } \\
(\mathrm{MPA})\end{array}$ & $\begin{array}{c}\text { Tensile } \\
\text { Strength } \\
(\mathrm{MPA})\end{array}$ \\
\hline $\begin{array}{l}\text { Clay } \\
\text { Brick }\end{array}$ & $2010^{-6}$ & 1450 & 0.2 & 6.38 & 0.3 \\
$\begin{array}{l}\text { Cement } \\
\text { Mortar }\end{array}$ & $2410^{-6}$ & 2500 & 0.22 & 8 & 0.7 \\
\hline
\end{tabular}

In the current study, $890 \mathrm{~mm} \times 755 \mathrm{~mm} \times 190 \mathrm{~mm}$ masonry wall has been produced. Horizontal mortar thickness is $20 \mathrm{~mm}$ and the vertical mortar thickness is $10 \mathrm{~mm}$. In order to collect the displacement data and understand the force-displacement relationship under vertical and lateral loads, three displacement gauges (LVDTs) have been placed on the right side of the wall as seen in Fig. 8.

The produced masonry wall has subjected to vertical and horizontal loads after 28 days, which is the waiting time for optimum strength for cement-based adhesives. The loading instrument, which can be seen in Fig. 8, can load up to $2000 \mathrm{kN}$ vertical load by virtually rigid high strength concrete slab on the top and lateral load is applied by a hydraulic rigid steel jack from the left side of the wall. The experiment started by applying $45 \mathrm{kN}$ vertical load to the masonry wall in 60 seconds to replicate the effect of the concrete floor and the beams over the wall in a masonry building. Lateral loading was started after completing vertical loading and have continued until the wall reached its ultimate strength. There are several damages can occur in the masonry walls under lateral loading. There can be slips and separations on vertical and horizontal contacts between mortar and masonry units and damage can occur on the masonry elements and mortar due to tensile stresses. The lateral loading takes around $300 \mathrm{sec}-$ onds for the wall to reach its ultimate strength. The force increment calculated during the lateral loading is between $0.4-0.5 \mathrm{kN} / \mathrm{s}$. During the lateral loading, lateral displacement sensors (LVDT) have collected the displacement data in three points while the lateral loading instrument
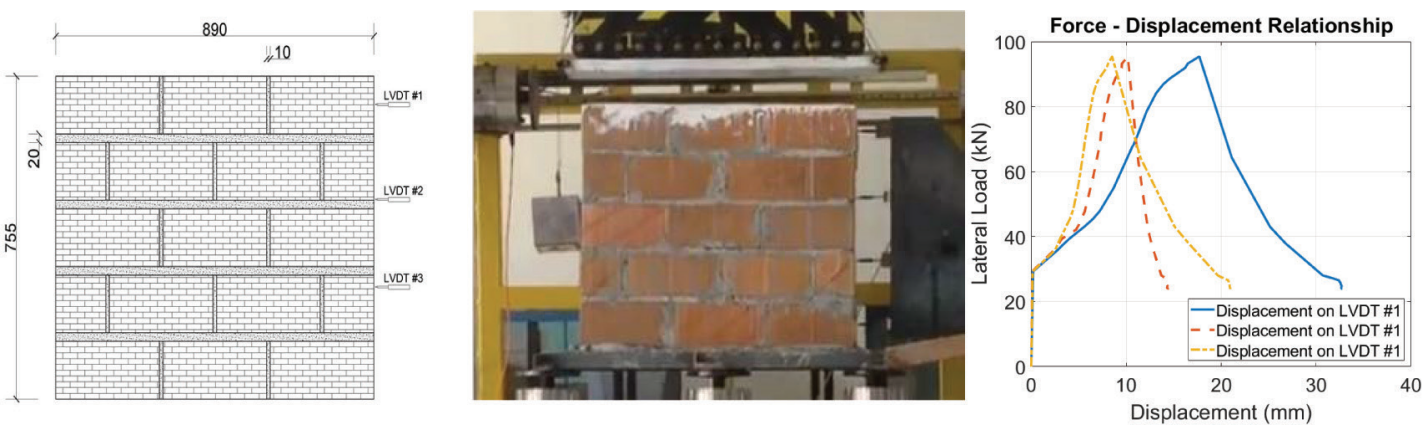

Fig. 8 LVDT placements, loading equipment and the load-displacement values 
collects applied force on the wall. At the end of the experiment, the lateral displacements were manually measured and crosschecked with the calibrated LVDT data to control the final displacement.

The force-displacement relationship data collected from three displacement gauges is shown in Fig. 8. The collected displacement data have been calibrated and converted to millimeters based on the formulation given by the manufacturer. After reaching the ultimate strength, the cracks and slips on the wall have been evaluated and documented.

\section{Finite element modelling}

Detailed FE models of the masonry wall were created based on the experimental results to evaluate the behavior and calibrate the model parameters. In general, there are two fundamental techniques, namely, micro and macro modeling, which can be used to simulate the mechanical behavior of masonry walls. Both of these techniques are used in this study to determine the mechanical properties and investigate the behavior of the masonry wall.

\subsection{Micro modeling}

The Micro-modeling technique can be accomplished by different approaches. One of these approaches is called detailed micro modeling. In detailed micro modeling, masonry units and mortar are modeled based on their mechanical properties and the contacts between masonry unit and mortar is accomplished by interfaces between these elements. On the other hand, simplified micro modeling is another approach in modeling masonry. In simplified micro modeling approach, the masonry units are modeled without mortar based on its mechanical properties while the behavior of mortar and contact properties are modeled through contact interfaces between masonry units.

In this study, Traction-Separation behavior has been used to simulate the behavior between the mortar and masonry units as contact interfaces, while material parameters of the mortar and masonry units are taken into account by experimental investigation. ABAQUS CAE has been used to simulate $3 \mathrm{D}$ models. The software has multiple definitions for traction separation laws includes, linear, exponential, and tabular which defines the separation part of the contact zone. In this research, user-defined tabular data have been used to define the separation part of the contact due to the high ductility of the contact zones. In addition to the traction separation laws, frictional behavior has been defined for horizontal and vertical interfaces as $45 \mathrm{kN}$ vertical load creates a friction between mortar and masonry units. In order to determine the interface parameters, the research on the literature gives an idea about the values of these interface parameters. In this research, the stiffness values for normal and tangential stiffness accepted in the range between the values of $0-1000 \mathrm{~N} / \mathrm{mm}$. In order to calculate the linear behavior of the interfaces and to match the linear part of the force-displacement relationship graph of the experimental results and numerical results, optimization process have been conducted based on the comparison force-lateral displacement graph. As a result of the optimization process, the stiffness coefficients of the interfaces determined as $500 \mathrm{~N} / \mathrm{mm}$. In addition, to define the non-linear behavior of the wall, damage initiation values should be defined for each interface member of the wall. The interfaces act as linear until the stresses on the interfaces reaches a certain value. The damage initiation values for normal and tangential behavior accepted in between 0-1 Mpa. The optimization processes have also been conducted to determine the damage initiation values and frictional values to match the non-linear part of the force-lateral displacement relationship.

The frictional and traction separation data used to simulate the experimental behavior of the wall is given in Table 2 .

The concrete damage plasticity models have been used to define the material properties of the masonry units and mortar. (Fig. 9) The plasticity models for the materials have been defined based on the determined experimental results.

The micro modeling of the wall has been completed by ABAQUS CAE. The assembly of the wall has been completed. The masonry units have been modeled as $3 \mathrm{D}$ stress element called "C3D8R" (Fig. 10). C4D8R is a general-purpose brick element with eight nodes and an integration point.

Contact interfaces have been defined as traction separation laws. After completing the elements, boundary conditions have been defined as the bottom part of the wall has pinned to the ground to restrain the displacements and free the rotations. As out of plane behavior of the wall is not in the interest of this study, the out of plane displacements of the nodes have been constrained. $45 \mathrm{kN}$ vertical load has been applied. The vertical displacements have

Table 2 Traction separation behavior

\begin{tabular}{cccccc}
\hline \multicolumn{2}{c}{ Stiffness Coefficients } & \multicolumn{3}{c}{$\begin{array}{c}\text { Damage Initiation } \\
\text { (Max Nominal Stresses) }\end{array}$} \\
\hline \multirow{2}{*}{ Friction } & $\begin{array}{c}\mathrm{Kss} \\
(\mathrm{N} / \mathrm{mm})\end{array}$ & $\begin{array}{c}\mathrm{Ktt} \\
(\mathrm{N} / \mathrm{mm})\end{array}$ & $\begin{array}{c}\text { Normal } \\
\text { Direction } \\
(\mathrm{MPA})\end{array}$ & $\begin{array}{c}\text { Shear 1 } \\
\text { Direction } \\
(\mathrm{MPA})\end{array}$ & $\begin{array}{c}\text { Shear 2 } \\
\text { Direction } \\
(\mathrm{MPA})\end{array}$ \\
\hline 0.07 & 500 & 500 & 0.5 & 0.71 & 0.71 \\
\hline
\end{tabular}




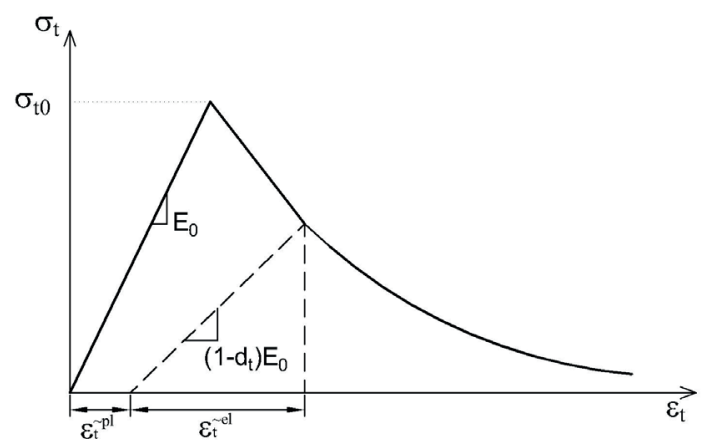

(a) Plasticity model under tension

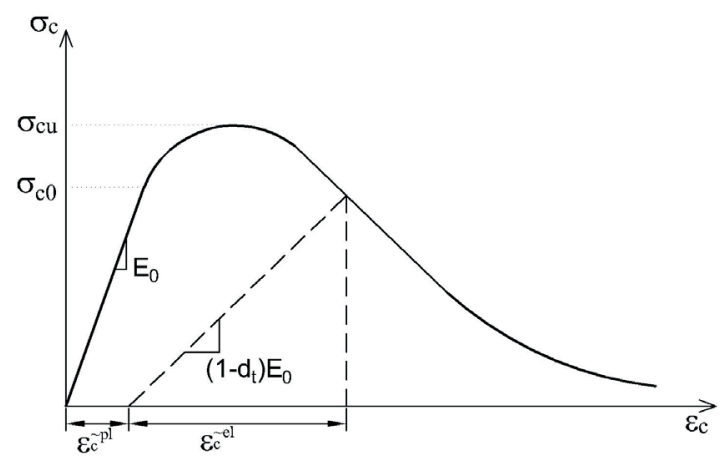

(b) Plasticity model under compression

Fig. 9 Concrete damage plasticity models

been constrained at the end of vertical loading and displacement-based lateral loading has started for $300 \mathrm{sec}-$ onds to determine the lateral strength of the masonry wall.

The base force-lateral displacement values have been extracted from the numerical results by a python script. The numerical model was calibrated using the experimental data by manually changing the properties of the masonry units and contact parameters. Consequently, a calibrated $3 \mathrm{D}$ numerical model of the wall has been obtained.

The force-displacement curves of the calibrated numerical model and the experimental results have been given in Fig. 11. Obviously, the discrepancies between the numerical and the experimental force-displacement curves obtained from various measurement locations remarkably low. The match between curves is sufficiently good even in the post-damage region.

Fig. 10 also shows the deformed shape of the wall and the principal strain distribution. The damage is assumed to occur when materials exceed elastic deformation limits and the stresses on the interfaces are more than damage initiation stresses. The experimentally obtained damage patterns are also marked on the same figure for comparison purposes. Since the results from both the numerical model and the experiments sufficiently agree, the calibrated model parameters can be used in the analysis of the walls with openings.
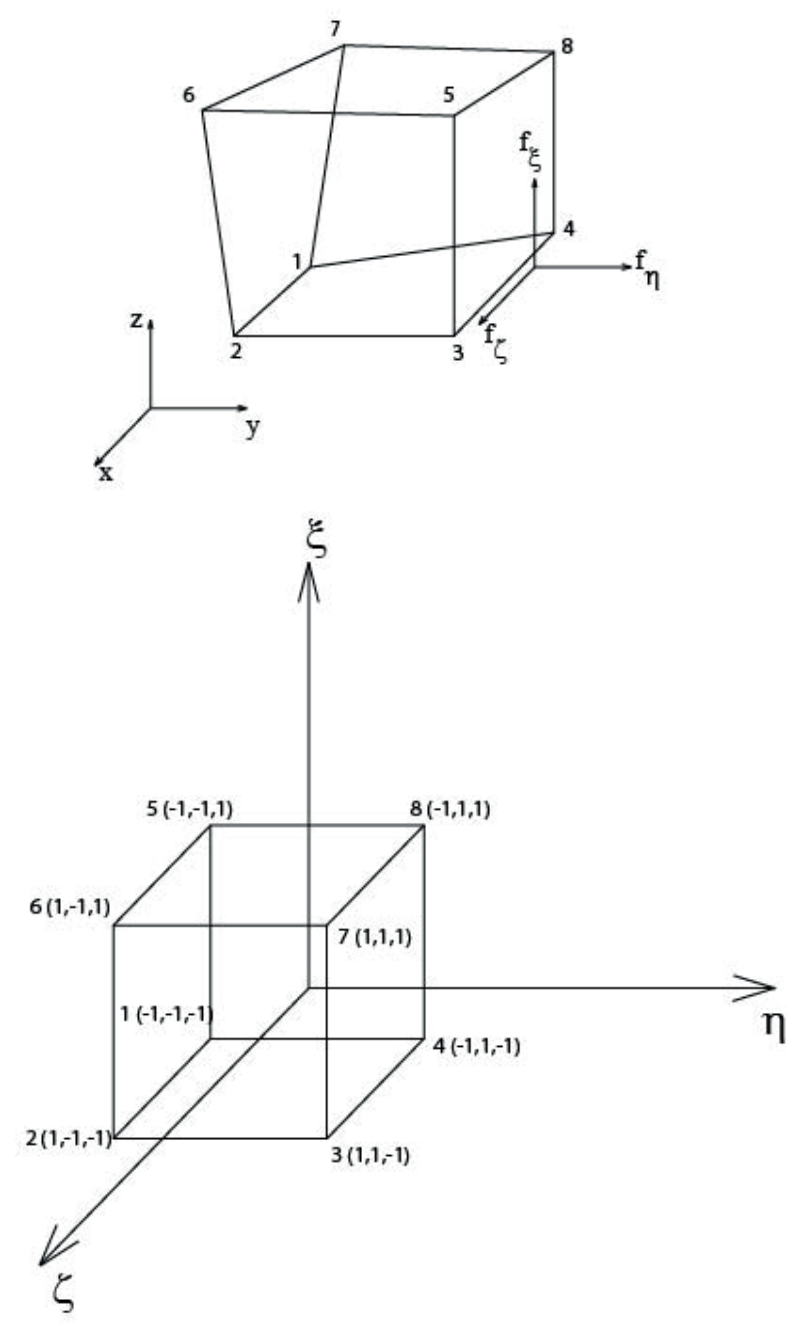

Fig. 10 3D Stress element

\subsection{Macro modelling}

In order to model a masonry wall as a composite structure, the material properties of a wall should be determined by experiments or by the structural codes. In this study, the experimental result and the corresponding material model will be used to determine the material properties of a gapless wall. The concrete damage plasticity model was used as a non-linear material model. As in the micro modeling, boundary conditions were defined and both vertical and lateral loadings were applied to the composite model. The material definition of the CDP model is estimated by the guidance of the experimental results as in the micro modeling. The density of the wall as a composite material have taken $21 \cdot 10^{-6} \mathrm{~N} / \mathrm{mm}^{3}$ calculated by the weight of the wall and volume of the wall as a composite element. The Young's modulus and of the wall have been determined based on the linear stiffness of the experimental results. The compression stress has been experimentally calculated one of the walls have been loaded with only vertical 


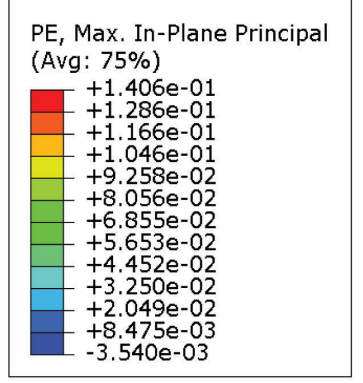
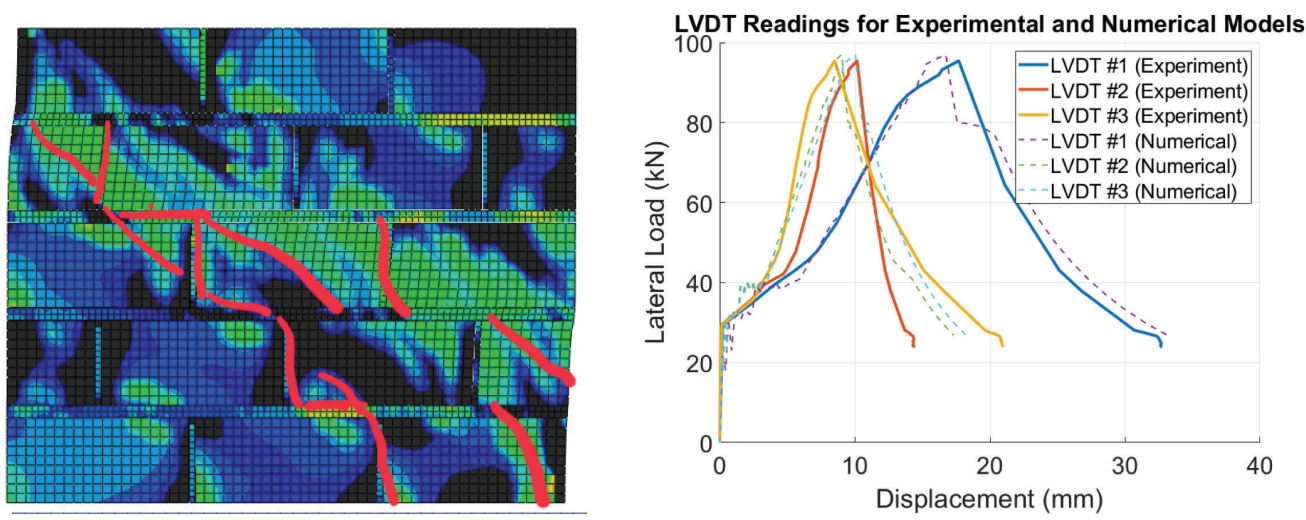

Fig. 11 Maximum principal stresses and force - displacement relationship

load and load-vertical displacement values have been analyzed. The load-vertical displacement relationship shows that the wall as a composite material shows linear behavior until 6.5 MPA. As a brittle material, the strain limit for the wall accepted as 0.003 .

In addition, tensile stress and strain values for linear and non-linear material values have been determined based on the force-lateral displacement relationship of the experimental results. The force-displacement relationship values have been calibrated while changing the tension stress and strain values based on the numerical results and optimal Concrete Damage Plasticity Values have been calculated.

The determined material properties of the CDP model is given in Table 3.

The force-displacement relationship of the macro model and the experimental results are compared, and convergence of the behaviors can be seen in Fig. 12(a) and 12(b). As a result, the modulus of elasticity of the masonry wall is determined as 550 MPA.

\subsection{Walls with openings}

After creating and calibrating the 3D FE model of the wall without openings, masonry walls that include openings with different sizes have been analyzed using the same mechanical and contact properties. All openings are located in the midst of the wall. The openings are designed as squares for adequate comparison and analysis. Ten models that have variable opening ratios in-between $5 \%$ and $50 \%$, have been created.

The resultant stresses of the walls have been shown in Fig. 13. As seen in the load distributions caused by lateral loading of the walls, while deformations have occurred on the masonry elements, slips and separations have also occurred on the contrast. The stress concentrations
Table 3 Concrete damage plasticity model material properties

\begin{tabular}{ccccccc}
\hline Density & $\begin{array}{c}\text { Young's } \\
\text { Modulus }\end{array}$ & $\begin{array}{c}\text { Poisson's } \\
\text { Ratio }\end{array}$ & Compression & \multicolumn{2}{c}{ Tensile } \\
$\left(\mathrm{N} / \mathrm{mm}^{3}\right)$ & (MPA) & & $\begin{array}{c}\text { Stress } \\
(\mathrm{MPA})\end{array}$ & Strain & $\begin{array}{c}\text { Stress } \\
(\mathrm{MPA})\end{array}$ & Strain \\
\hline $2110^{-6}$ & 550 & 0.2 & 6.5 & 0 & 0.12 & 0.02 \\
& & & 7 & 0.003 & 0.64 & 0.008 \\
\hline
\end{tabular}

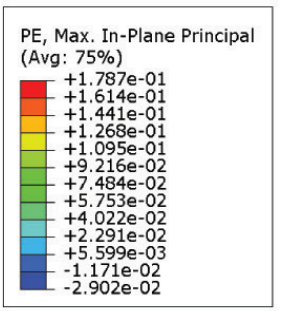

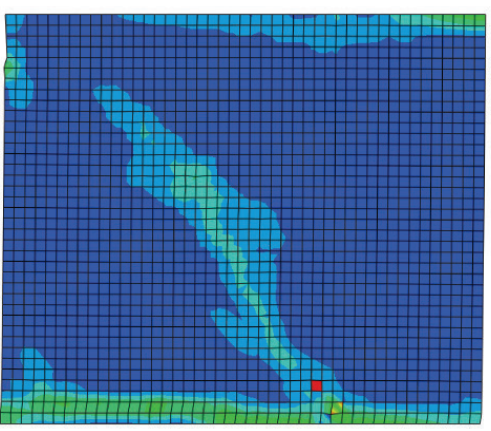

(a) In-plane plastic strains

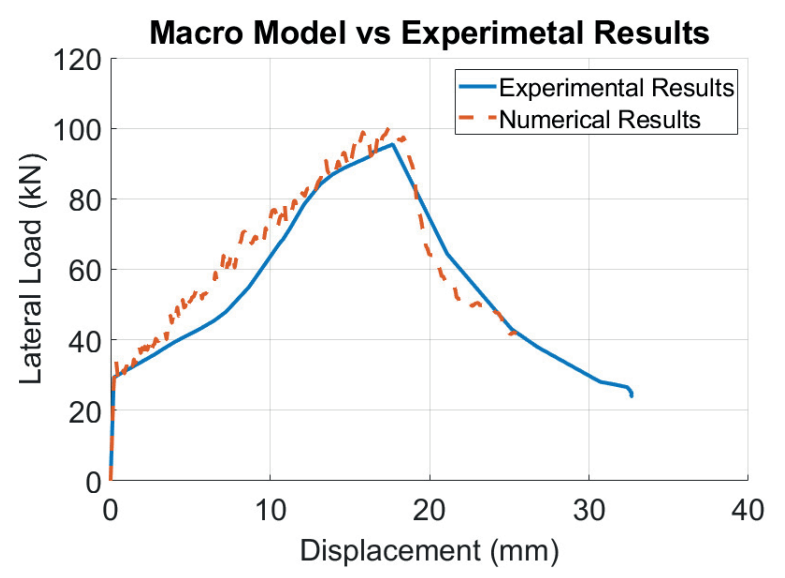

(b) Force-lateral displacement relationship of numerical model and experimental

Fig. 12 Results of macro model of the walls 

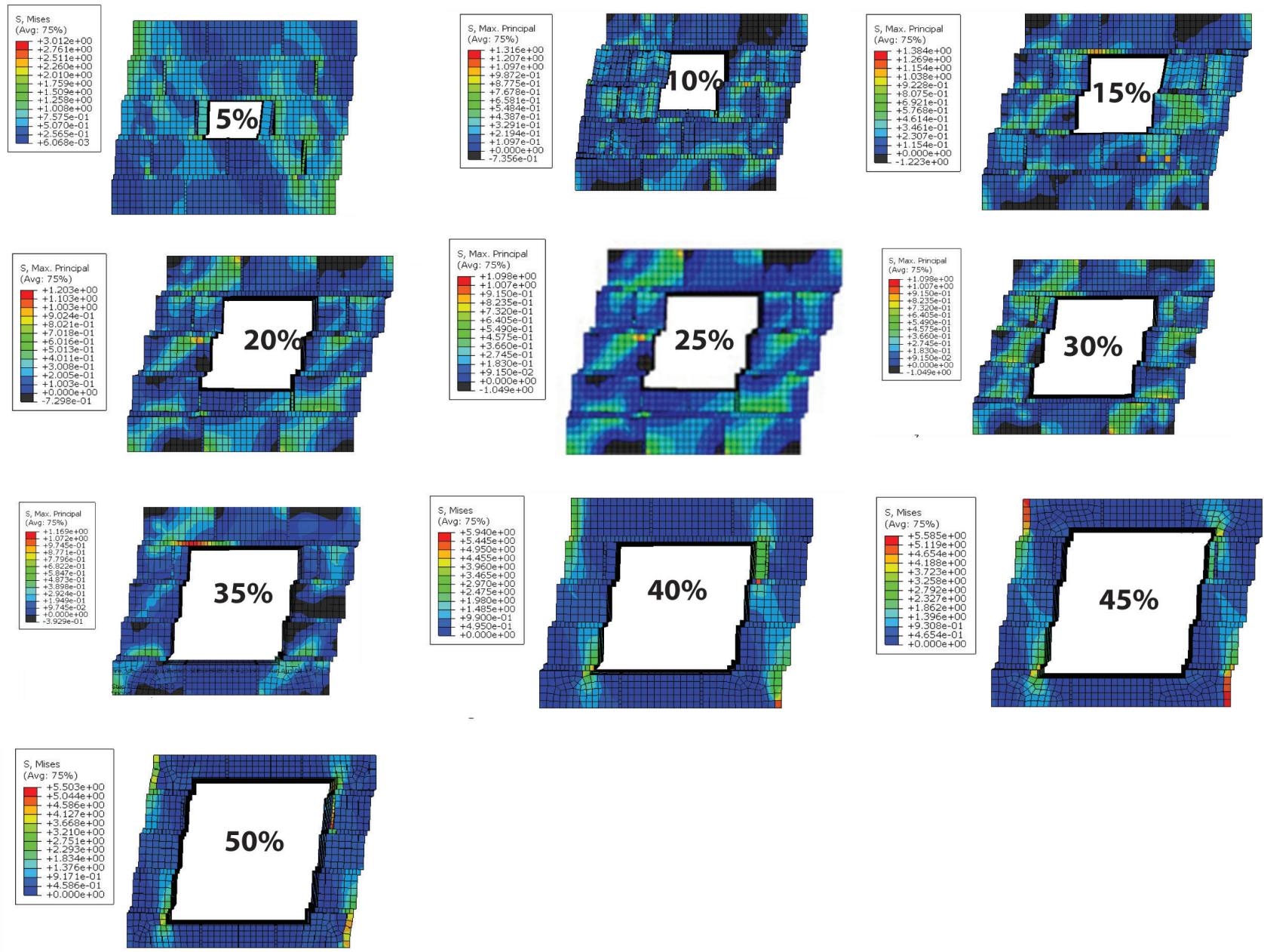

Fig. 13 Resultant stresses of walls with the openings

occurred on the corners of the openings until the slip and separation occur. Non-linear behavior was seen on mortar and brick for the specimens with less than $15 \%$ openings while no non-linear behavior was seen on the specimens with more than $20 \%$ openings. Due to the low contact area on the specimens with more than $20 \%$ openings, slip occurs before any non-linear behavior can be seen.

Fig. 14 shows the force-displacement relationships of the wall without opening and walls with the openings. The change in the ductility of the wall because of the openings and the change in the ultimate strengths of the walls can be seen in the results. In the force-displacement plot, change of the linear behavior as a change in the slope, which defines the decrease of Young's modulus based on the openings in the wall, can be seen, as well.

As expected, the strength and stiffness of the walls have been decreasing due to the openings. Examining the linear behavior of the wall shows us that while the yielding point of the wall has decreased as a result of the openings in the walls, young's modulus of the walls has been decreased as well. The relationship between the ratio of the opening area and modulus of elasticity $(\mathrm{MoE})$ has been shown in Fig. 15.

As seen in Fig. 15, the decrease of young's modulus, which is the result of stiffness loss of the walls due to the opening, can be seen.

Regression analysis shows that the change of the modulus elasticity can be calculated by given Eq. (4).

$$
E_{d}=E_{\text {gapless }} \cdot\left(1-1.24 A_{g}^{0.8356}\right)
$$

Where Ed is the young's modulus of the wall, Egapless is the gapless modulus of elasticity of the wall that is determined by experiments or calculated by the structural codes, and Ag is the gap percentage of the wall. In order to determine the lateral response of a building, the material properties of the units that are creating the buildings should be known. As a result, the material properties of the walls should be determined to evaluate the building thus the properties have been determined for both walls without an opening and the wall with the openings. 

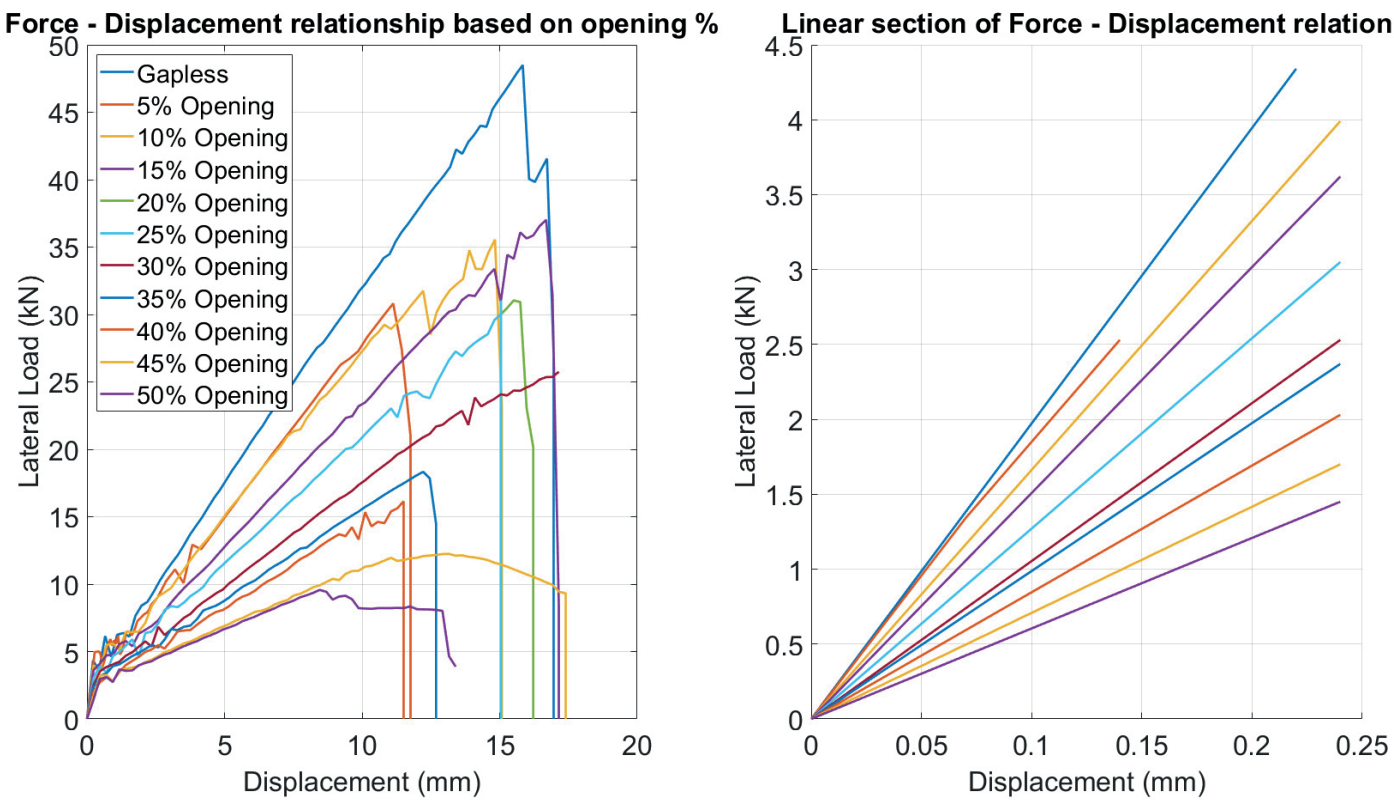

Fig. 14 Force Displacement Relationships

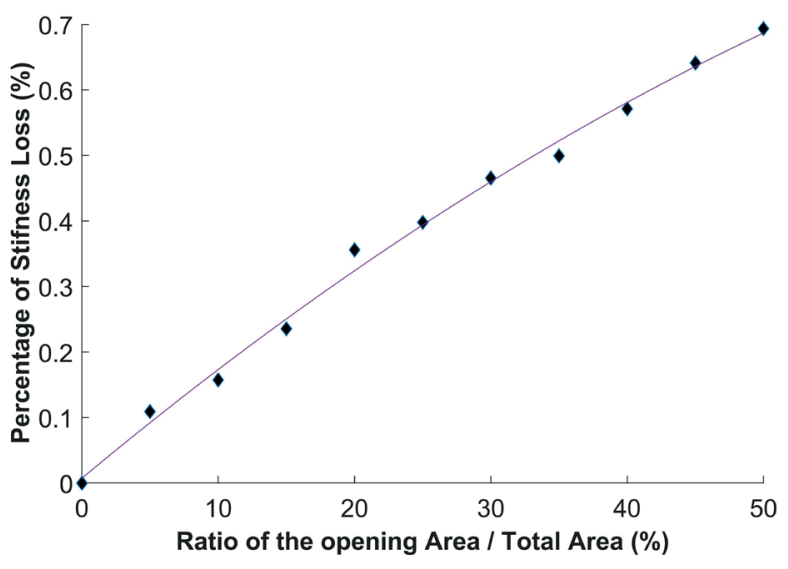

Fig. 15 Stiffness loss based on openings

\section{Numerical analysis and verification of the proposed model}

Although creating an accurate micro model of the masonry wall makes it possible to investigate its behavior and response in detail, it is more practical and computationally inexpensive to adopt macro-modeling approaches while creating the numerical model of large-scale structures. In a macro modeling approach, the conventional way is to use the same homogenized material parameters for all components of the structure. However, due to the openings on the walls, the stiffness decreases and the stiffness loss in a wall of a masonry building plays an important role regarding its response due to its load-bearing capacity. Hence, calculating the modulus of elasticity of each wall considering the openings and creating numerical models based on these material properties provides a way to improve the accuracy of the macro models.
In the presented study, the analysis of the buildings has been conducted through the macro-modeling approach. The structure has been modeled by using ABAQUS CAE. Due to the same materials used on the investigated buildings, linear and non-linear material properties that were extracted from experimental and numerical results have been used to model the investigated buildings. The 3D FE models of the investigated masonry buildings can be seen in Fig. 16.

\subsection{Comparison of the experimental and the numerical modal parameters considering constant Modulus of Elasticity}

Firstly, the same material properties for the masonry walls have been used whether the walls have openings or not. In this case, the modulus of elasticity of the walls was calculated as $550 \mathrm{Mpa}$. The first the natural frequencies and modal shapes for Building A Building B and Building $\mathrm{C}$ are given in Fig. 17.

\subsection{Comparison of the experimental and the numerical modal parameters considering the degraded Modulus of Elasticity}

On the other hand, the degradation of wall stiffness due to the openings is well known. Hence, the percentages of openings for each wall have been calculated and modulus of elasticities determined by Eq. (4) have been assigned to each wall. The modal analysis results extracted by OMA and numerical models are given in Table 4.

The natural frequencies of the buildings extracted by these FE models are presented in Figs. 18 through 20. 

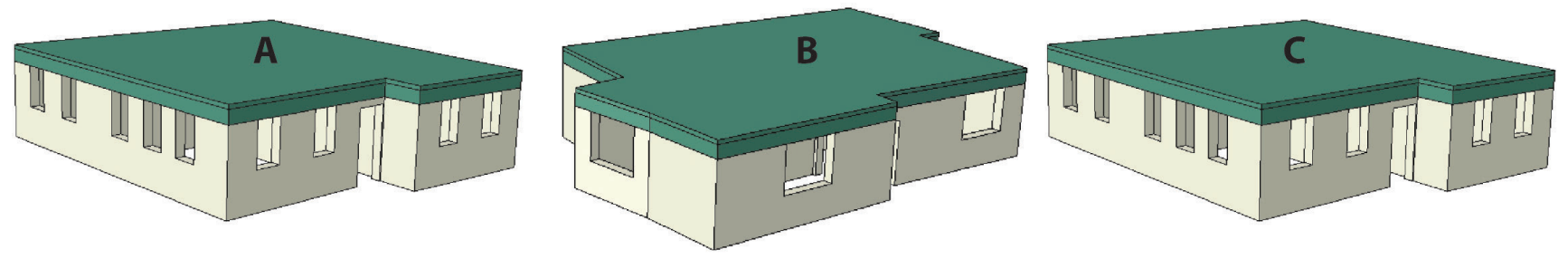

Fig. 16 3D FE models
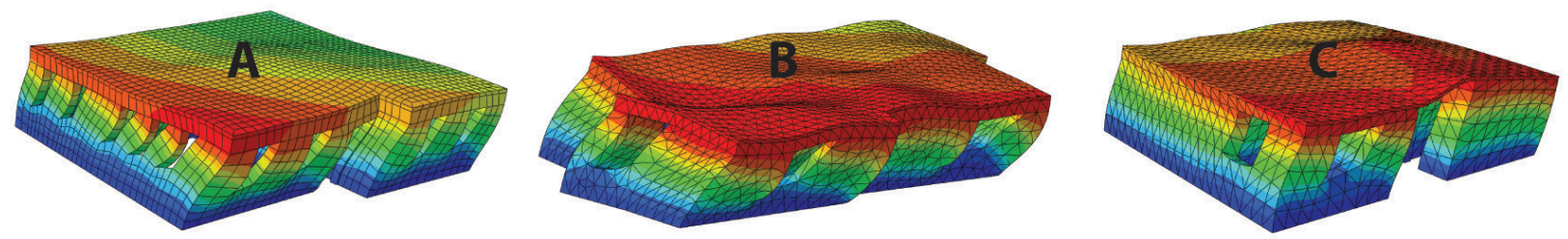

Fig. 17 First natural frequencies for Building A, $B$ and $C$ using constant $\operatorname{MoE}\left(f_{A 1}=13.93 \mathrm{~Hz}, \mathrm{f}_{\mathrm{Bl}}=14.04 \mathrm{~Hz}, \mathrm{f}_{\mathrm{Cl}}=13.54 \mathrm{~Hz}\right)$

Table 4 Natural frequencies extracted by experimental and numerical analysis

\begin{tabular}{lcccccccccc}
\hline & & \multicolumn{3}{c}{ Mode \#1 (Frequency) } & \multicolumn{3}{c}{ Mode \#2 (Frequency) } & \multicolumn{3}{c}{ Mode \#3 (Frequency) } \\
Building \# & $\begin{array}{c}\text { Modulus of } \\
\text { Elasticity }\end{array}$ & $\begin{array}{c}\text { OMA } \\
(\mathrm{Hz})\end{array}$ & $\begin{array}{c}\text { FE Model } \\
(\mathrm{Hz})\end{array}$ & $\begin{array}{c}\text { Relative } \\
\text { Difference } \\
(\%)\end{array}$ & $\begin{array}{c}\text { OMA } \\
(\mathrm{Hz})\end{array}$ & $\begin{array}{c}\text { FE Model } \\
(\mathrm{Hz})\end{array}$ & $\begin{array}{c}\text { Relative } \\
\text { Difference } \\
(\%)\end{array}$ & $\begin{array}{c}\text { OMA } \\
(\mathrm{Hz})\end{array}$ & $\begin{array}{c}\text { FE Model } \\
(\mathrm{Hz})\end{array}$ & $\begin{array}{c}\text { Relative } \\
\text { Difference } \\
(\%)\end{array}$ \\
\hline Building A & Constant (550 Mpa) & 11.50 & 13.93 & 21.2 & 13.31 & 14.58 & 9.5 & 16.42 & 17.37 & 5.8 \\
Building B & Constant (550 Mpa) & 12.00 & 14.05 & 17.1 & 17.16 & 15.00 & 12.6 & - & - & - \\
Building C & Constant (550 Mpa) & 12.28 & 13.54 & 10.3 & 13.38 & 14.07 & 5.1 & 15.12 & 17.39 & 15.0 \\
Building A & Degraded & 11.50 & 12.55 & 9.1 & 13.31 & 13.33 & 0.2 & 16.42 & 15.99 & 2.6 \\
Building B & Degraded & 12.00 & 11.32 & 5.7 & 17.16 & 15.32 & 10.7 & - & - & - \\
Building C & Degraded & 12.28 & 12.31 & 0.3 & 13.38 & 12.56 & 6.2 & 15.12 & 15.52 & 2.6 \\
\hline
\end{tabular}
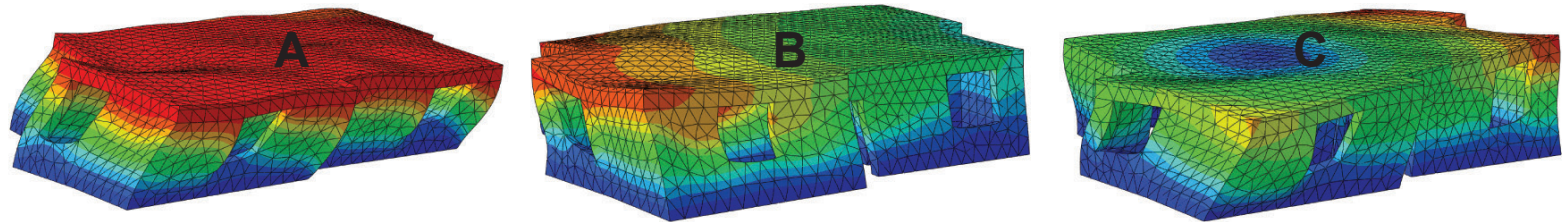

Fig. 18 Natural frequencies for Building A using degraded $\mathrm{MoE}\left(\mathrm{f}_{\mathrm{A} 1}=12.55 \mathrm{~Hz}, \mathrm{f}_{\mathrm{A} 2}=13.33 \mathrm{~Hz}, \mathrm{f}_{\mathrm{A} 3}=13.54 \mathrm{~Hz}\right)$
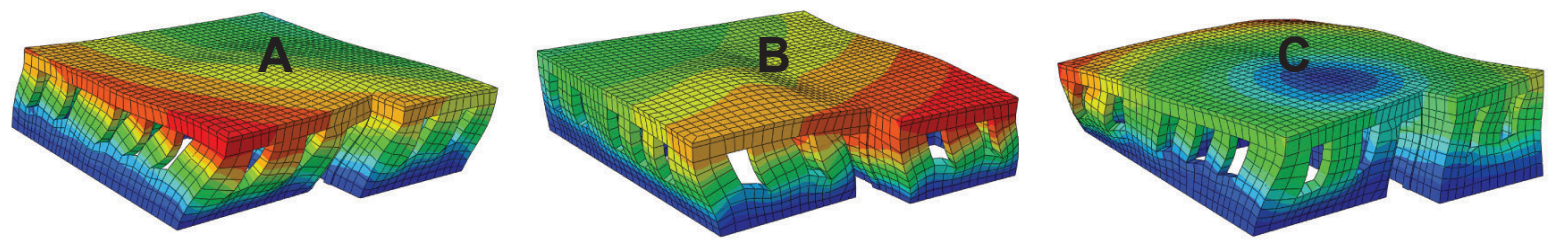

Fig. 19 Natural frequencies for Building A using degraded $\operatorname{MoE}\left(\mathrm{f}_{\mathrm{A} 1}=12.68 \mathrm{~Hz}, \mathrm{f}_{\mathrm{A} 2}=12.68, \mathrm{~Hz}, \mathrm{f}_{\mathrm{A} 3}=15.32 \mathrm{~Hz}\right)$
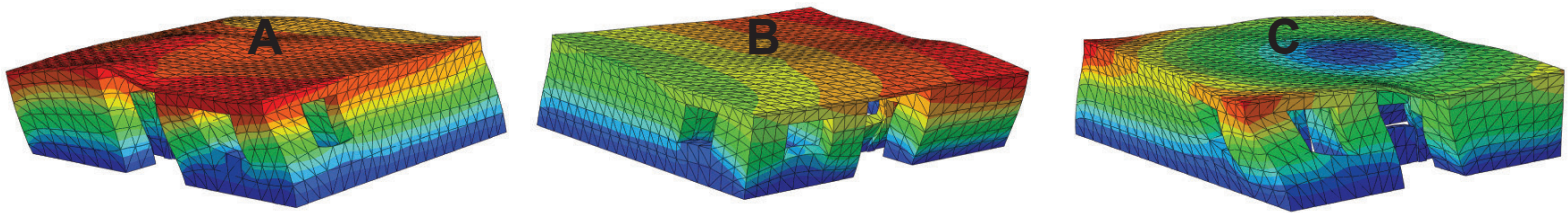

Fig. 20 Natural frequencies for Building A using degraded $\mathrm{MoE}\left(\mathrm{f}_{\mathrm{A} 1}=12.31 \mathrm{~Hz}, \mathrm{f}_{\mathrm{A} 2}=12.56, \mathrm{~Hz}, \mathrm{f}_{\mathrm{A} 3}=15.52 \mathrm{~Hz}\right)$ 
Obviously, the results are more accurate than the results from the FE models in which a constant modulus of elasticity for all walls was used. The modal extractions show that using the same modulus of elasticities gives a relative difference in-between $5.1 \%-21.2 \%$ in natural frequencies of the studied buildings while the relative differences in results based on degraded modulus elasticities are around $0.3 \%-13.33 \%$ for investigated buildings.

\subsection{Comparison linear time history results under seismic actions}

The linear time history analyses have completed to determine the results of seismic actions. Various seismic records have been evaluated and seismic records from Imperial Walley (1979) have been used due to the similarity of the frequency spectrum of the designated earthquake and the target spectrum determined from Turkish Seismic Code. The seismic records can be seen in Fig. 21.

The local seismic target spectrum has been determined in the Turkish Seismic Code based on the location of the buildings. In addition, spectral matching of the seismic data have been completed based on the local characteristics of the seismic zone of the buildings. Fig. 22 show the target spectrum based on the geographical location of the buildings and the response spectrum of the matched seismic records.

The matched seismic accelerations have applied to the buildings and base shear forces and the top displacements of the buildings have been compared to determine the seismic effect on the buildings. Figs. 23-25 show the base shear forces for each direction and the top values for both buildings designed with constant modulus of elasticity and degraded modulus of elasticities.

As seen in Figs. 23-25, buildings designed with degraded modulus of elasticities face more seismic forces that the buildings designed with constant modulus of elasticities. Seismic accelerations create $60 \%, 130 \%$, and $65 \%$ more base shear force on direction 1 for the Building A, Building B and Building C. Also, $60 \%$, $30 \%$ and, $49 \%$ more base shear force is observed on Direction 2.

Figs. 26-28 shows the top displacements of the masonry buildings under seismic action for both designed by constant modulus of elasticity and degraded modulus of elasticity.

As seen in the in the Figs. 26-28, the lateral displacement on the center of the building have been increased $83 \%$ to $300 \%$ due to degraded modulus of elasticities in Direction 1. On the other hand, there is $75 \%$ to $100 \%$ increase in Direction 2. These lateral drifts will cause the increase in
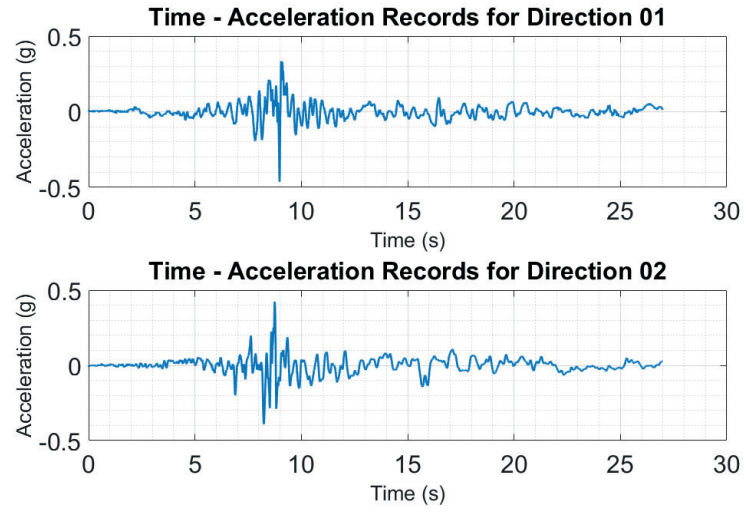

Fig. 21 Imperial Valley ceismic records

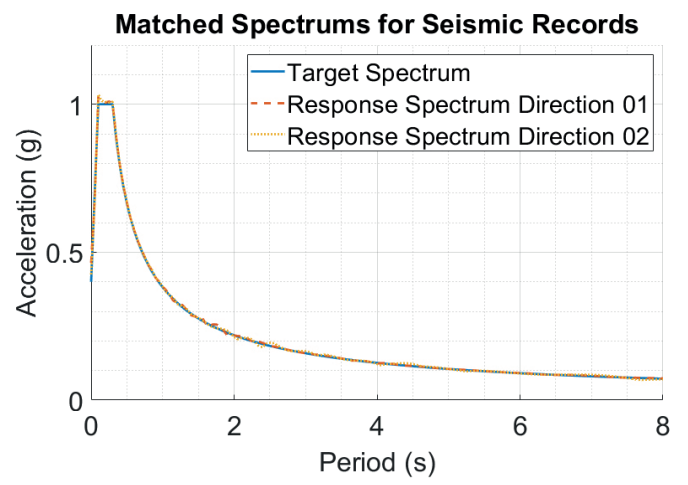

Fig. 22 Target spectrum and matched response spectrum

maximum principal stresses on the walls and increase the risks under seismic loads. Fig. 29 shows the maximum principal stresses on Building A under seismic loads.

The analyses show that while maximum principal stresses on model designed with constant modulus of elasticities is $2.2 \mathrm{Mpa}$ the maximum principal stress of the model with degraded modulus of elasticities is $3.3 \mathrm{Mpa}$.

\section{Conclusions}

This research investigates the effects of the openings in a masonry building under seismic forces. The material experiments have been conducted to define the material properties for masonry walls; a formulation has been defined to determine the stiffness degradation on the masonry walls due to the openings. Operational modal analysis was completed on investigated buildings and finite element models of the buildings and material properties have been verified. Finally, linear time history analysis has been completed to determine the effect of seismic acceleration under degraded modulus of elasticities.

- Experimental tests have been carried out on a masonry wall which has been constructed as the same materials as in the investigated masonry buildings. The damage under lateral loading have been investigated and 

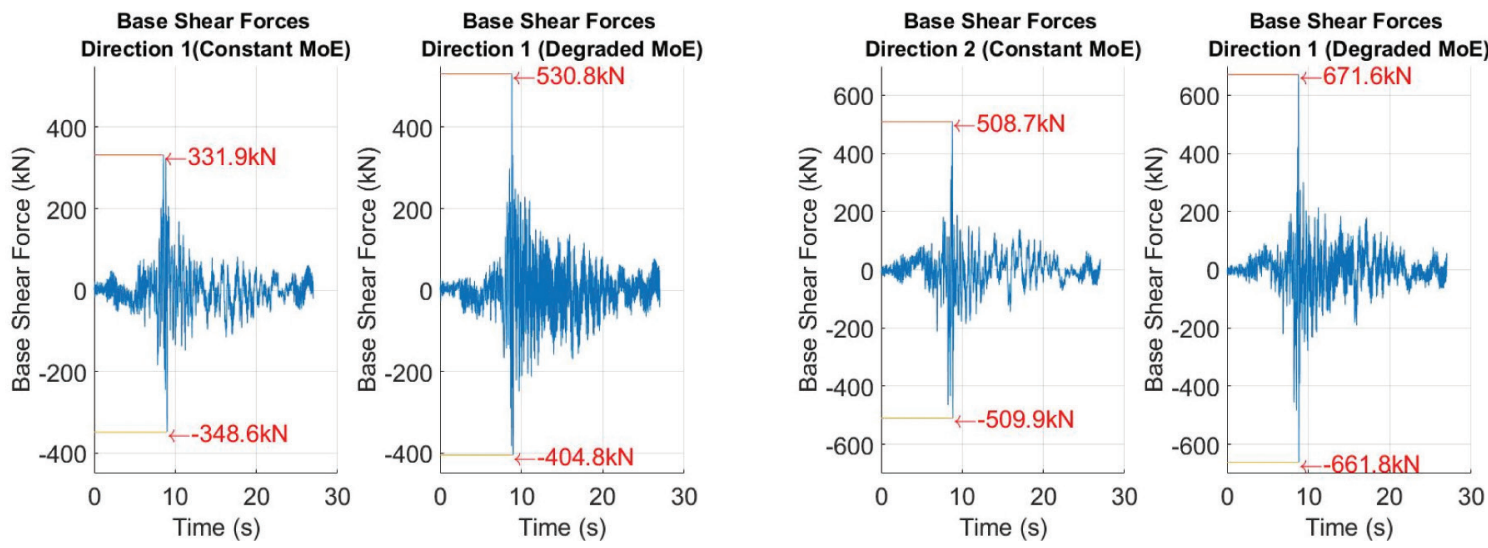

Fig. 23 Base shear forces on Building A
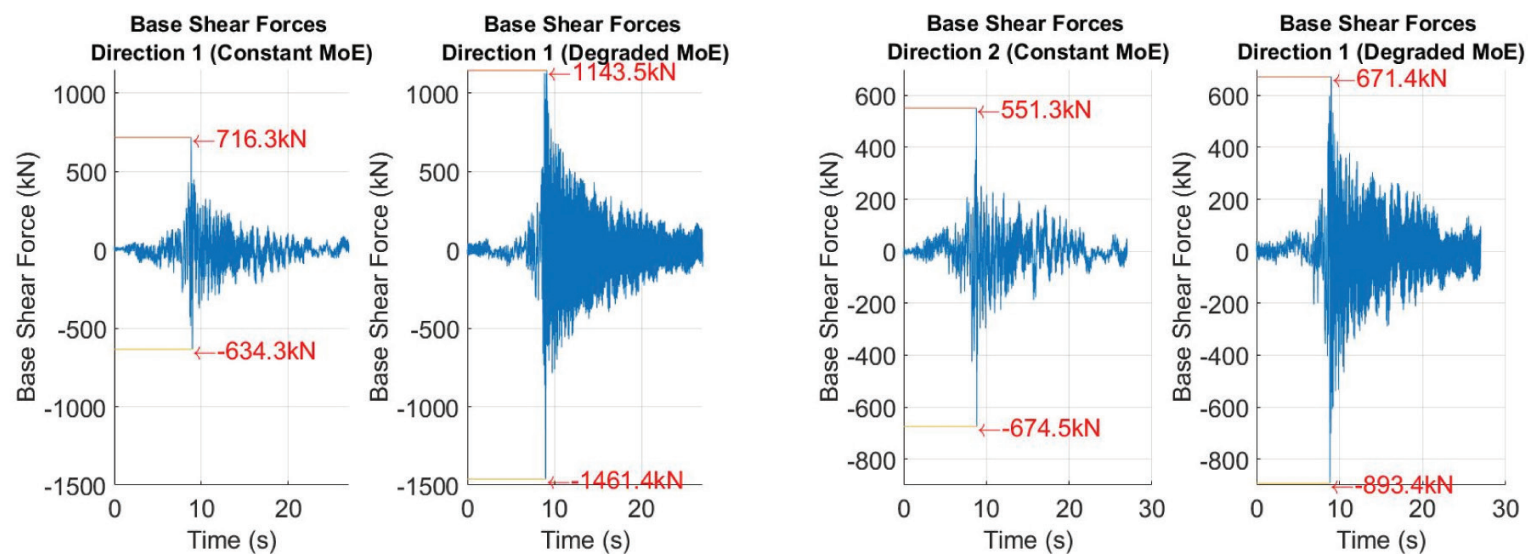

Fig. 24 Base shear forces on Building B
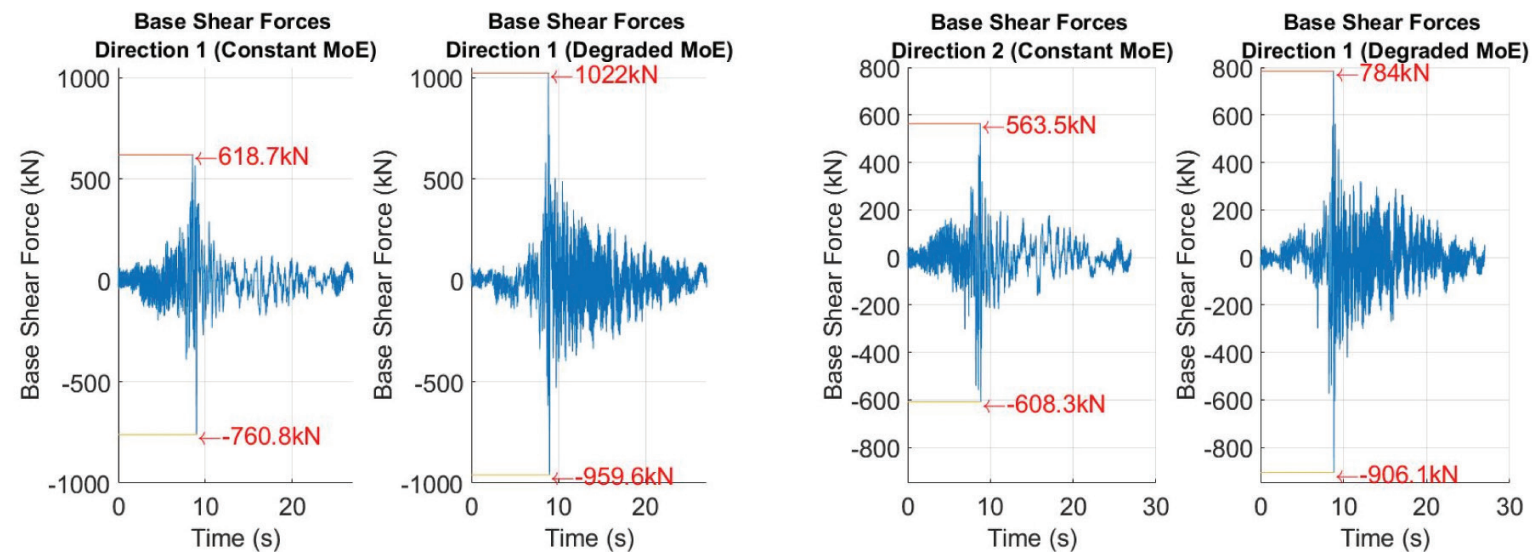

Fig. 25 Base shear forces on Building C

force-displacement relationship on the experimental wall have been observed. 3D micro modeling of the masonry wall has been developed based on the experimental results and various openings on the walls have been defined on the 3D micromodels. The developed models with the openings have been analyzed and the degradation on stiffness and strength have been calculated based on the opening percentage. A formulation has been developed based on the experimental and numerical results to define the modulus of elasticity based on the openings.

- The masonry walls showed ductile behavior due to contact ductility between mortar and masonry units despite the brittle behavior of combining elements. 3D macro modeling of the masonry wall has been developed and material parameters for the Concrete 

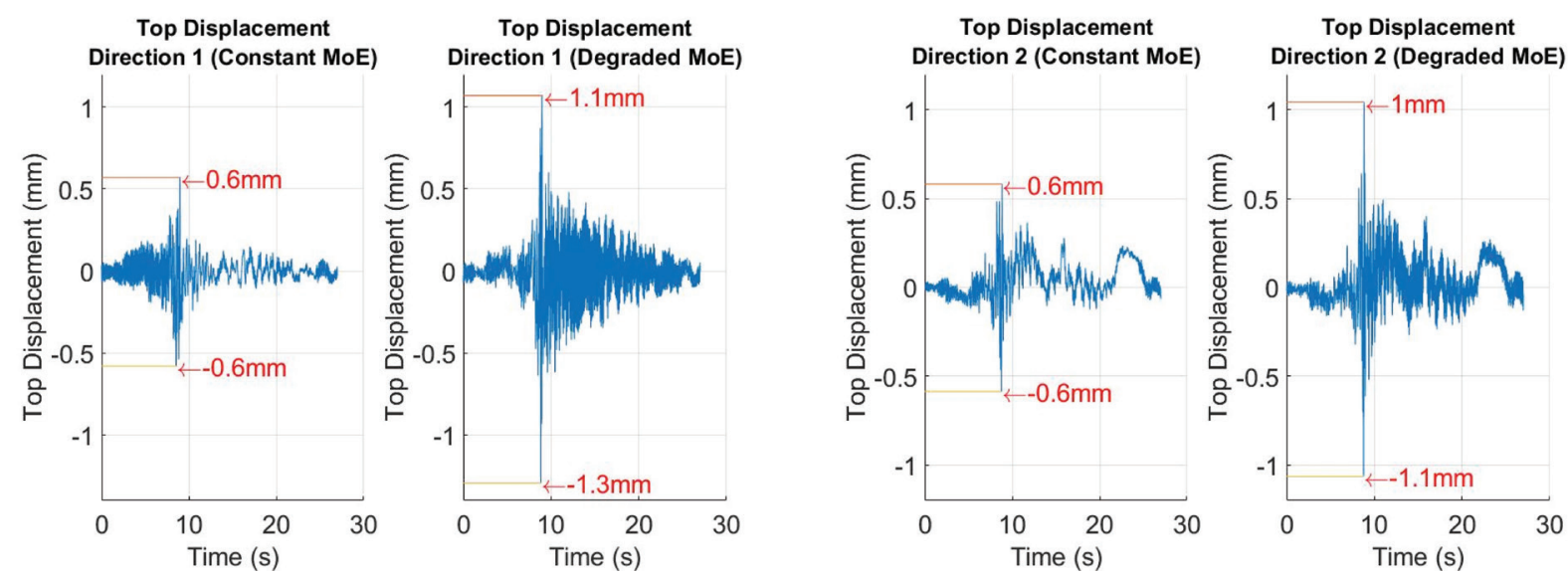

Fig. 26 Top displacement of Building A
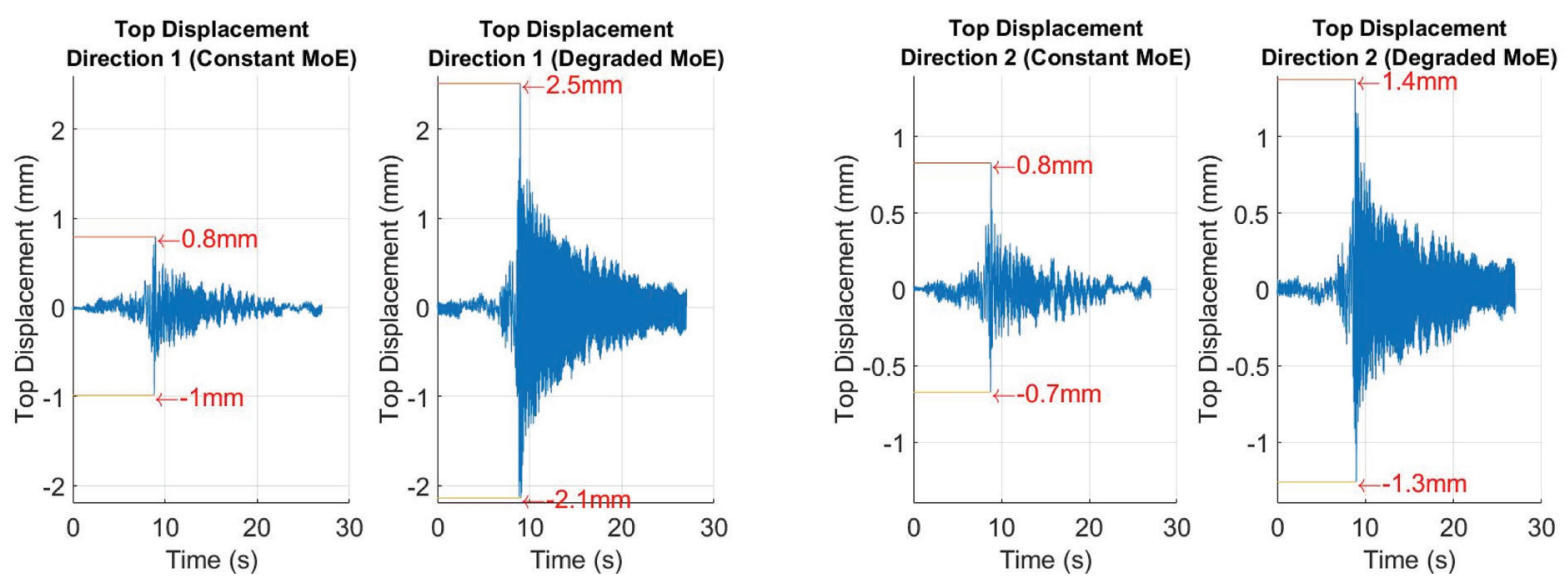

Fig. 27 Top displacement of Building B
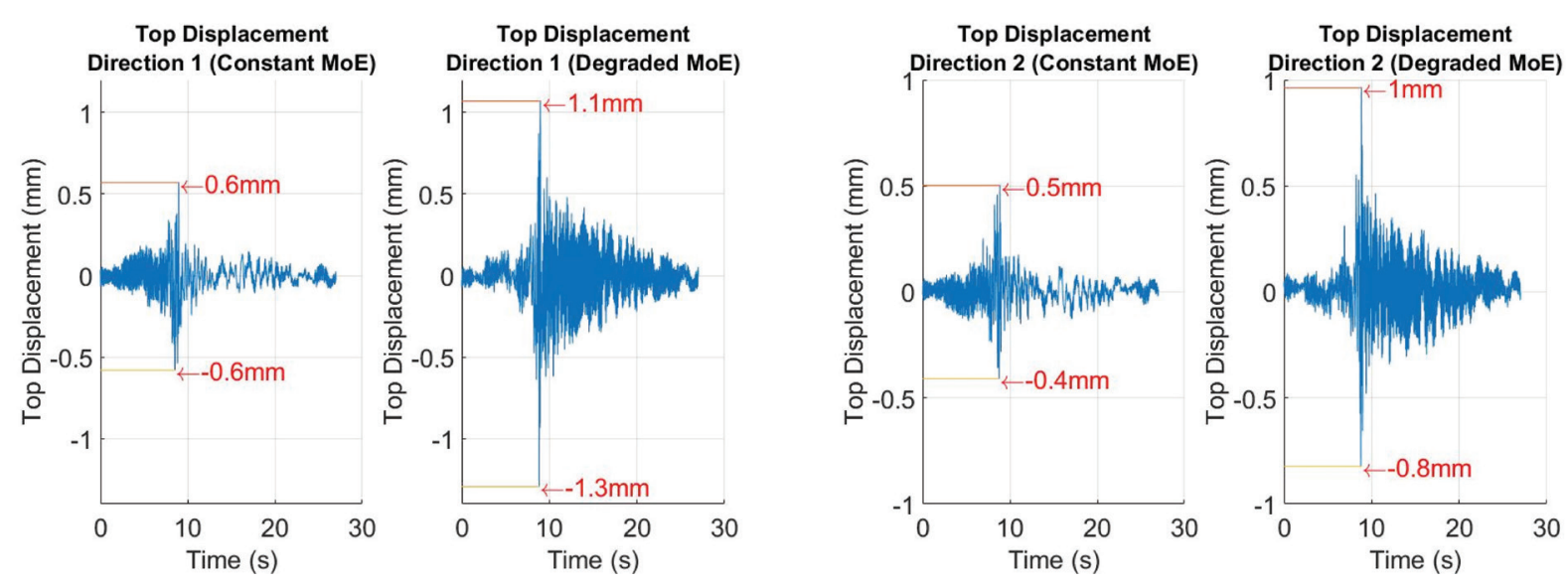

Fig. 28 Top displacement of Building C

Damage Plasticity model have been determined for composite modeling. The force displacement relationship from the experimental results and calculated modulus of elasticity by macro modeling of the wall shows that the specified masonry walls shows ductile behavior under lateral loading.
- Finite element model of three masonry buildings have been developed.

- During the modeling, the openings on each wall have been evaluated based on the percentage of the openings and degraded modulus of elasticity have been used for the walls. 


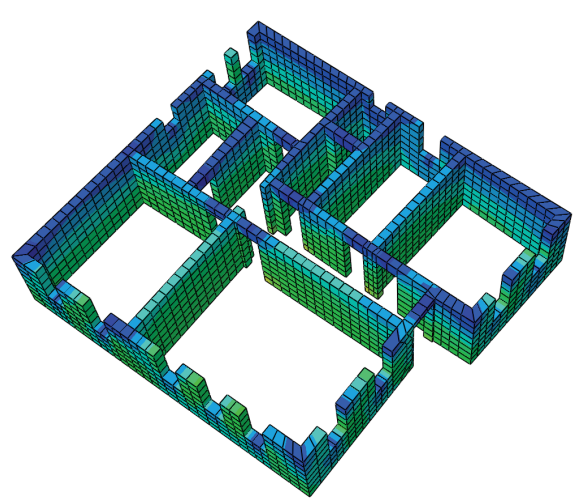

Constant $\mathrm{MoE}$

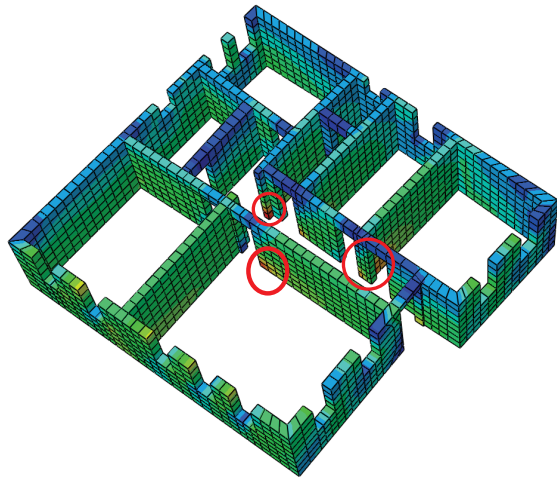

Degraded MoE

Fig. 29 Principal stresses under seismic loads-Building A

- The fundamental frequencies and mode shapes of three masonry buildings have been calculated based on on-site measurements and FE models. The extracted modal parameters from OMA, calculated modal parameters from numerical models have been compared. While modal parameters calculated from the buildings defined with constant modulus of elasticities match with $5.1 \%-21.2 \%$ relative difference, the modal parameters calculated from buildings with degraded modulus of elasticities match with

\section{References}

[1] Boscato, G., Reccia, E., Cecchi, A. "Non-destructive experimentation: Dynamic identification of multi-leaf masonry walls damaged and consolidated", Composites Part B: Engineering, 133, pp. 145$165,2018$.

https://doi.org/10.1016/j.compositesb.2017.08.022

[2] Çalik, İ., Bayraktar, A., Türker, T., Karadeniz, H. "Structural dynamic identification of a damaged and restored masonry vault using Ambient Vibrations", Measurement, 55, pp. 462-472, 2014. https://doi.org/10.1016/j.measurement.2014.05.030

[3] Ercan, E. "Assessing the impact of retrofitting on structural safety in historical buildings via ambient vibration tests", Construction and Building Materials, 164, pp. 337-349, 2018. https://doi.org/10.1016/j.conbuildmat.2017.12.154

[4] Kouris, L. A. S., Penna, A., Magenes, G. "Seismic damage diagnosis of a masonry building using short-term damping measurements", Journal of Sound and Vibration, 394, pp. 366-391, 2017. https://doi.org/10.1016/j.jsv.2017.02.001

[5] Sancibrian, R., Lombillo, I., Sarabia, E. G., Boffill, Y., Wong, H., Villegas, L. "Dynamic identification and condition assessment of an old masonry chimney by using modal testing", Procedia Engineering, 199, pp. 3410-3415, 2017. https://doi.org/10.1016/j.proeng.2017.09.485

[6] Zhou, Y., Prader, J., Weidner, J., Dubbs, N., Moon, F., Aktan, A. E. "Structural Identification of a Deteriorated Reinforced Concrete Bridge", Journal of Bridge Engineering, 17(5), pp. 774-787, 2012. https://doi.org/10.1061/(ASCE)BE.1943-5592.0000309
$0.3 \%-13.33 \%$ relative difference. The results show that modeling with the calculated modulus of elasticities for each wall gives results that are more accurate.

- The linear time history analysis shows that the buildings designed with degraded modulus of elasticities face with $60 \%-130 \%$ more base shear force in Direction 1 and $30 \%-60 \%$ more base shear force in Direction II. The accurate calculation of the modulus of elasticities is essential on calculation of the seismic forces.

[7] Bayraktar, A., Türker, T., Altunişik, A. C. "Experimental frequencies and damping ratios for historical masonry arch bridges", Construction and Building Materials, 75, pp. 234-241, 2015. https://doi.org/10.1016/j.conbuildmat.2014.10.044

[8] Le, T.-P., Paultre, P. "Modal identification based on the time-frequency domain decomposition of unknown-input dynamic tests", International Journal of Mechanical Sciences, 71, pp. 41-50, 2013. https://doi.org/10.1016/j.ijmecsci.2013.03.005

[9] Torres, W., Almazán, J. L., Sandoval, C., Boroschek, R. "Operational modal analysis and FE model updating of the Metropolitan Cathedral of Santiago, Chile", Engineering Structures, 143, pp. 169-188, 2017.

https://doi.org/10.1016/j.engstruct.2017.04.008

[10] Aras, F. "Monitoring the dynamic properties of a nine-story reinforced concrete building during its demolition", Structural Control and Health Monitoring, 26(11), Article ID: e2456, 2019. https://doi.org/10.1002/stc.2456

[11] Lourenço, P. B., Rots, J. G., Blaauwendraad, J. "Two approaches for the analysis of masonry structures: Micro and macro-modeling", Heron, 40(4), pp. 313-340, 1995. [Online]. Available: http:// resolver.tudelft.nl/uuid:c39b29ab-3c75-47db-9cb5-bf2b1c678f1f

[12] AlGohi, B. H., Baluch, M. H., Rahman, M. K., Al-Gadhib, A. H., Demir, C. "Plastic-Damage Modeling of Unreinforced Masonry Walls (URM) Subject to Lateral Loading", Arabian Journal for Science and Engineering, 42, pp. 4201-4220, 2017. https://doi.org/10.1007/s13369-017-2626-8 
[13] Alfano, G., Sacco, E. "Combining interface damage and friction in a cohesive-zone model", International Journal for Numerical Methods in Engineering, 68(5), pp. 542-582, 2006.

https://doi.org/10.1002/nme.1728

[14] Giambanco, G., Di Gati, L. "A cohesive interface model for the structural mechanics of block masonry", Mechanics Research Communications, 24(5), pp. 503-512, 1997. https://doi.org/10.1016/s0093-6413(97)00055-4

[15] Guinea, G. V., Hussein, G., Elices, M., Planas, J. "Micromechanical modeling of brick-masonry fracture", Cement and Concrete Research, 30(5), pp. 731-737, 2000. https://doi.org/10.1016/S0008-8846(00)00228-3

[16] Lee, M. J., Lim, J. M., Lee, B. C. "Finite Element Analysis of an Adhesive Joint Using the Cohesive Zone Model and Surface Pattern Design of Bonding Surfaces", The Journal of Adhesion, 89(3), pp. 205-224, 2013.

https://doi.org/10.1080/00218464.2013.739042

[17] Serpieri, R., Albarella, M., Sacco, E. "A 3D microstructured cohesive-frictional interface model and its rational calibration for the analysis of masonry panels", International Journal of Solids and Structures, 122-123, pp. 110-127, 2017. https://doi.org/10.1016/j.ijsolstr.2017.06.006

[18] Yuen, T. Y. P., Deb, T., Zhang, H., Liu, Y. "A fracture energy based damage-plasticity interfacial constitutive law for discrete finite element modelling of masonry structures", Computers and Structures, 220, pp. 92-113, 2019. https://doi.org/10.1016/j.compstruc.2019.05.007

[19] Zhang, S., Taheri Mousavi, S. M., Richart, N., Molinari, J.-F., Beyer, $\mathrm{K}$. "Micro-mechanical finite element modeling of diagonal compression test for historical stone masonry structure", International Journal of Solids and Structures, 112, pp. 122-132, 2017. https://doi.org/10.1016/j.ijsolstr.2017.02.014

[20] Alberto, A., Antonaci, P., Valente, S. "Damage analysis of brick-tomortar interfaces", Procedia Engineering, 10, pp. 1151-1156, 2011. https://doi.org/10.1016/j.proeng.2011.04.191

[21] Giambanco, G., Rizzo, S., Spallino, R. "Numerical analysis of masonry structures via interface models", Computer Methods in Applied Mechanics and Engineering, 190(49-50), pp. 6493-6511, 2001.

https://doi.org/10.1016/S0045-7825(01)00225-0

[22] Mojsilović, N. "Strength of masonry subjected to in-plane loading: A contribution", International Journal of Solids and Structures, 48(6), pp. 865-873, 2011. https://doi.org/10.1016/j.ijsolstr.2010.11.019

[23] Sacco, E., Lebon, F. "A damage-friction interface model derived from micromechanical approach", International Journal of Solids and Structures, 49(26), pp. 3666-3680, 2012. https://doi.org/10.1016/j.ijsolstr.2012.07.028

[24] Turon, A., Dávila, C. G., Camanho, P. P., Costa, J. "An engineering solution for mesh size effects in the simulation of delamination using cohesive zone models", Engineering Fracture Mechanics, 74(10), pp. 1665-1682, 2007. https://doi.org/10.1016/j.engfracmech.2006.08.025

[25] Lourenço, P. J. B. B. "Computational strategies for masonry structures", PhD, Delft University of Technology, 1996. [online] Available at: http://www.hms.civil.uminho.pt/arq/fich/1996_PhD_ PBLourenco.pdf
[26] Asteris, P. G., Syrmakezis, C. A. "Strength of Unreinforced Masonry Walls under Concentrated Compression Loads", Practice Periodical on Structural Design and Construction, 10(2), pp. 133-140, 2005. https://doi.org/10.1061/(ASCE)1084-0680(2005)10:2(133)

[27] Asteris, P. G., Tzamtzis, A. D. "Non-Linear Analysis of Masonry Shear Walls", In: Proceedings of the Sixth International Masonry Conference, London, UK, 2002, pp. 1-6.

[28] Capozucca, R. "Experimental response of historic brick masonry under biaxial loading", Construction and Building Materials, 154, pp. 539-556, 2017. https://doi.org/10.1016/j.conbuildmat.2017.07.186

[29] Giamundo, V., Sarhosis, V., Lignola, G. P., Sheng, Y., Manfredi, G. "Evaluation of different computational modelling strategies for the analysis of low strength masonry structures", Engineering Structures, 73, pp. 160-169, 2014. https://doi.org/10.1016/j.engstruct.2014.05.007

[30] Syrmakezis, C. A., Asteris, P. G. "Masonry Failure Criterion under Biaxial Stress State", Journal of Materials in Civil Engineering, 13(1), pp. 58-64, 2001. https://doi.org/10.1061/(ASCE)0899-1561(2001)13:1(58)

[31] Plevris, V., Asteris, P. G. "Modeling of masonry failure surface under biaxial compressive stress using Neural Networks", Construction and Building Materials, 55, pp. 447-461, 2014. https://doi.org/10.1016/j.conbuildmat.2014.01.041

[32] Berto, L., Saetta, A., Scotta, R., Vitaliani, R. "An orthotropic damage model for masonry structures", International Journal for Numerical Methods in Engineering, 55(2), pp. 127-157, 2002. https://doi.org/10.1002/nme.495

[33] Di Nino, S., D'Annibale, F., Luongo, A. "A simple model for damage analysis of a frame-masonry shear-wall system", International Journal of Solids and Structures, 129, pp. 119-134, 2017. https://doi.org/10.1016/j.ijsolstr.2017.09.007

[34] Pelà, L., Cervera, M., Roca, P. "An orthotropic damage model for the analysis of masonry structures", Construction and Building Materials, 41, pp. 957-967, 2013. https://doi.org/10.1016/j.conbuildmat.2012.07.014

[35] Abdulla, K. F., Cunningham, L. S., Gillie, M. "Simulating masonry wall behaviour using a simplified micro-model approach", Engineering Structures, 151, pp. 349-365, 2017. https://doi.org/10.1016/j.engstruct.2017.08.021

[36] Addessi, D., Marfia, S., Sacco, E., Toti, J. "Modeling Approaches for Masonry Structures", The Open Civil Engineering Journal, 8(1), pp. 288-300, 2014. https://doi.org/10.2174/1874149501408010288

[37] Brincker, R., Zhang, L., Andersen, P. "Modal Identification from Ambient Responses using Frequency Domain Decomposition", In: IMAC 18 Proceedings of the International Modal Analysis Conference (IMAC), San Antonio, TX, USA, 2000, pp. 625-630, [Online] Available at: https://vbn.aau.dk/en/publications/modal-identification-from-ambient-responses-using-frequency-domai-2

[38] Herlufsen, H., Andersen, P., Gade, S., Møller, N. "Identification techniques for operational modal analysis - an overview and practical experiences", In: Proceedings of the $1^{\text {st }}$ International Operational Modal Analysis Conference, Copenhagen, Denmark, 2005, pp. 242-254. [Online] Available at: https://pdfs.semanticscholar.org/flfa/ a3b4032d7f8211b70c2acd9e49f9c5e3dfb6.pdf?_ga=2.189501675. 1995318634.1599031687-755765893.1594746010 